\title{
Welcome to YOUR new \\ Canadian Journal of Plastic Surgery
}

$\mathrm{T}$ he Canadian Journal of Plastic Surgery (CJPS) has begun a new and exciting phase in its history. It is now owned by the Canadian Society of Plastic Surgeons, and I am privileged to be the new Editorin-Chief.

Over the past several months, the Journal has made changes we hope will be enthusiastically supported by and will benefit the entire Society membership and plastic surgery as a whole. The most obvious change you will all see instantly - our cover is now RED. Red was chosen for its vibrant colour and as a play on words - we want the 'RED JOURNAL' to be READ. This is, in fact, the fundamental principle that will drive all decisions regarding the Journal - it must be read. And to take that further, to be read, we understand it must provide value. As a professional journal, it must educate and inform the profession it serves, and I hope it does this now and for the many years to come.

We have undertaken many new initiatives and, judging by the commitment we have received from more than 50 society members so far, there are many great things still to come. The Journal has expanded, and each issue will now be a 60-page book. It will continue to publish original articles and review articles, but will limit the publication of case reports at the present time. New sections include oral and written Board practice questions and answers, Financial and Practice Management, Invited Special Topics and Canadian Consensus opinions.
The Journal is now fully online for submissions with the capability of handling and reviewing videos (www.pulsus.com/plastics). The Journal will soon have an APP that will allow easy portability, article searching and video viewing. Pulsus Group, who will continue to publish the Journal, has a fee-based editing service (www.PulsusEdit. com) for authors of manuscripts that require substantive editing before submission. The cost of this service for society members will be covered by the editorial office. Please contact Editor-in-Chief, Dr Edward Buchel, at ebuchel@exchange.hsc.mb.ca or Kimberly Dalke at kdalke2@exchange.hsc.mb.ca for further details.

Finally, I wish to acknowledge that we have received a generous unrestricted education grant from Johnson \& Johnson for the ongoing support of the CJPS Editor-in-Chief office. This grant allowed the development of a journal that educates and informs plastic surgeons, residents and others involved in the care of plastic surgery patients. I hope and trust you will enjoy YOUR Journal, participate in YOUR Journal and, most importantly, be proud of YOUR Journal.

Sincerely,

Edward W Buchel MD, Editor-in-Chief Canadian Journal of Plastic Surgery 